\section{BEA-007 WHAT DO YOUR EMPLOYEES THINK ABOUT TOTAL QUALITY MANAGEMENT SYSTEMS?}

doi:10.1136/ejhpharm-2013-000276.618

'D Haider, ${ }^{1} \mathrm{~K}$ Klein, ${ }^{2} \mathrm{GPG}$ Bouchand. 'Sozialmedizinisches Zentrum Süd - Kaiser-FranzJosef-Spital und Gottried von Preyer'schem Kinderspital, Pharmacy, Vienna, Austria; 'Université de Nantes, UFR des sciences pharmaceutiques et biologiques, Nantes, France

Background A Total Quality Management System (TOMS) is being implemented in the pharmacy of a 1456-bed hospital in Vienna, Austria. The hospital pharmacy consists of five departments; dispensary service, clinical pharmacy service, pharmaceutical compounding, cytotoxic reconstitution, medicines information. Purpose First to look at the expectations of pharmacy staff relating to the structural reorganisation needed as a result of the implementation of a TOMS, and second to gather suggestions for quality improvements in their everyday work.

Materials and Methods Data collection was achieved using a non-disguised questionnaire consisting of 8 questions. Two open-ended questions (unstructured, key ideas), five closed-ended dichotomous questions (followed by contingency questions) and one question using a rating scale from one to ten were asked. All staff members of the pharmacy were asked to fill out the survey. For data evaluation a Grounded Theory-based coding system was used. Results Establishing a TOMS was deemed to be important by $90.5 \%$ of the respondents. A total of 21 usable responses were received, for a response rate of $72.4 \%$. The areas in which a TOMS was deemed to be important were: improvements of work processes $(\sim 30 \%)$, quality control $(\sim 20 \%)$, communication $(\sim 15 \%)$ and training $(\sim 10 \%)$. Further we found that the respondents wanted to improve quality in work processes, through implementation of regular training $(\sim 20 \%)$, better communication $(\sim 15 \%)$ and better working conditions $(\sim 15 \%)$.

Conclusions From this project we can state clearly that pharmacy staff welcomes the introduction of a TQMS to their workplace. TQMS was expected to be most important for improving work processes. The frequency of importance of communication and training being highlighted by the respondents was of interest and should be borne in mind during the implementation process.

No conflict of interest. 